\title{
Cognitive Poetry: Theoretical Framework for the Application of Cogni- tive Psychology Techniques to Poetic Text
}

\author{
Anatoliy V. Kharkhurin \\ American University of Sharjah, UAE \\ E-mail address: akharkhurin@aus.edu
}

ARTICLE INFO

\section{Keywords:}

Poetry

Cognitive

Psychology

Metaphor

Vygotsky

\begin{abstract}
A B STRACT
This article presents a theoretical framework for the author's experimental work in contemporary poetry, which has received the term cognitive poetry. In contrast to cognitive poetics, which applies the principles of cognitive psychology to interpret poetic texts, cognitive poetry applies these principles to produce poetic texts. The theoretical considerations of cognitive poetry are based on the assumption that one of the major purposes of creative work is to elicit an aesthetical reaction in the beholder. The aesthetical reaction to poetic texts could be achieved via their satiation with multiple meanings presented through multiple sensory modalities. Cognitive poetry employs techniques developed in cognitive psychology to explicitly address cognitive processes underlying the construction of multiple conceptual planes. The following techniques are discussed: priming, the Stroop effect, multimodal and multilingual presentations. The applications of these techniques are illustrated with examples of poetic texts produced by the author.
\end{abstract}

\section{Article history:}

Received 12 January 2016

Received in revised form 14 April 2016

Accepted 15 April 2016

ISSN: 2354-0036

DOI: 10.1515/ctra-2016-0005

Over the last hundred years, poetry has undergone major changes, which reflect variations in cultural, social, ideological, political and economical landscapes. These modifications manifest themselves primarily in conceptual and stylistic aspects of poetic text. Experimental methods and techniques used to process this text crossed the boundaries of this genre and brought poetry to the adjacent territories. Visual poetry enriches poetic text with elements of visual art. Sound poetry brings the text to its primordial form - music. Poetry films transform the text into a video. Cognitive poetry uses the techniques of cognitive psychology to process the text.

Before I proceed to discussion of a theoretical framework of cognitive poetry, I eliminate any possible confusion that might occur due to similarity in the terms cognitive poetry and cognitive poetics. In contrast to cognitive poetics (e.g., Stockwell, 2002; Tsur, 1992), which applies the principles of cognitive psychology to interpret poetic texts, cogni- 
tive poetry applies these principles to produce poetic texts. Cognitive poetics combines the efforts of cognitive psychology and literary theory to interpret linguistic patterns of literary text as correlates of human cognition. Cognitive poetry analyzes human cognition to find alternative techniques of constructing poetic text, which would increase its aesthetic value.

\section{THEORETICAL FRAMEWORK}

The premises of cognitive poetry are grounded in Vygotsky's (1925/1971) theory of aesthetical reaction. Aesthetics plays a central role in creative endeavour (Kharkhurin, 2014). The aesthetic value of a work of art touches upon recipients' emotions and elicits their aesthetical reactions. The latter according to Vygotsky, increases as a result of a complication of creative work. Additional (parallel) interpretations complicate the plot, trigger curiosity, arouse conjectures and divide attention. This encourages greater psychic energy consumption and thereby an increase in aesthetical reaction: "The greater the expenditure of nervous energy, the more intense is the effect produced by the work of art” (Vygotsky, 1925/1971, p. 205). Any work of art - if it claims to elicit strong aesthetical reaction - should include several psychic planes with opposite force. The contradiction between conflicting psychological aspects of creative work results in an 'explosion' of psychic energy, elicits cathartic experience (cf. Aristotle, 2012), which in turn reinforces aesthetical reaction. For Vygotsky, "aesthetic response, above all, is a response that annihilates our nervous energy; it is an explosion" (1925/1971, p. 205). He explains the multifaceted nature of creative work in the following passage:

In order to be really alive, the tragic character must be composed of contradictory traits and must carry us from one emotion to another. The physiognomic incongruency among the various details of the facial expression in a portrait is the basis for our emotional reaction; and the psychological non-coincidence of the various factors expressing the character in a tragedy is the basis for our tragic sympathy. By forcing our feelings to alternate continuously to the opposite extremes of the emotional range, by deceiving them, splitting them and piling obstacles in their way, the tragedy can obtain powerful emotional effect (Vygotsky, 1925/1971, p. 194).

Thus, Vygotsky emphasizes the aesthetic merits of integrating different, often opposite conceptual planes in creative work. This idea stipulates the core methodology employed by cognitive poetry.

This approach finds support in creativity literature. An ability to establish distant associations that link concepts from distant categories constitutes divergent thinking (Guilford, 1967), which is considered by many scholars as one of the major components of creativity (e.g., Lubart, 2000). Divergent thinking involves a broad search for infor- 
mation and generation of numerous novel alternative answers or solutions to a problem. It occurs in an unconscious mind, where attention is defocused (e.g., Kasof, 1997; Mendelsohn, 1976) and thought is associative (e.g., Koestler, 1964; Mednick \& Mednick, 1967; Ward, Smith, \& Vaid, 1997). Its unconscious functioning can be explained by an automatic spreading activation mechanism (McClelland \& Rumelhart, 1985) that simultaneously triggers a large number of mental representations. Thus, divergent thinking refers to the ability to process simultaneously a large number of unrelated conceptual representations. Therefore, presentation of incongruent conceptual planes within a work of art would trigger an individual's divergent thinking.

Simultaneous activation of different conceptual planes may also help overcome 'structured imagination' (Ward, 1994). A number of studies in various domains of creative production show that the semantic structure of a category has a substantial influence on what people produce (Ward, Patterson, Sifonis, Dodds, \& Saunders, 2002). Structured imagination limits individuals' thinking outside the box; that is, people have difficulties violating the conceptual boundaries of a standard category when creating a new exemplar of that category. For example, when participants were asked to create an alien creature in Ward's alien creature invention task they could not help but produce one that greatly resembled a humanoid creature. This creature is comprised of the surface properties of a human; that is, it is bilaterally symmetrical and has four limbs and two eyes. This example illustrates that we tend to preserve the standard category boundaries, to think inside the box even when asked to be creative. In this respect, creative thinking may benefit from actively engaging conceptual representations from multiple categories (Kharkhurin, 2009). This multifaceted processing in turn may render a mental state in which at least several sets of category properties become available for the thought process. This outcome may potentially help to overcome the limitations of structured imagination and therefore facilitate non-standard creative thinking.

In fact, many models of creative thinking emphasize conceptual ambivalence. For example, Rothenberg (1996) described Janusian thinking as the ability for "actively conceiving multiple opposites or antitheses simultaneously" (p. 207). This concept is similar to another of Rothenberg's (1979) ideas of homospatial thinking that "consists of actively conceiving two or more discrete entities occupying the same space, a conception leading to the articulation of new identities" (p. 7). Koestler (1968) introduced the concept of bisociation, which he defined as the ability for "combining two hitherto unrelated cognitive matrices in such a way that a new level is added to the hierarchy, which contains the previously separate structures as its members" (p. 183). Another model talked about remote 
associations - an ability of creative individuals to build connections between unrelated ideas or objects (Mednick, 1962).

Presenting multiple conceptual planes within one work triggers metaphorical thinking. Metaphor was found to play an important role in creative thinking in general (e.g., Lubart \& Getz, 1997; Silvia \& Beaty, 2012; Ward et al., 1997) and in creative writing in particular (e.g., Plotnik, 2007; Williams-Whitney, Mio, \& Whitney, 1992). A metaphor is an analogy between two instances conveyed by the use of one instead of another. For example, an instance of non-creative thinking describes a rose as thorn plant with a short life cycle. Another instance of non-creative thinking presents an individual with a sorrowful life as one whose antagonistic behaviour is intended to protect him against intrusion from the outer world. Now, these two instances produced by let's say, a gardener and a psychologist respectively can be combined by a poet in a poetic line. This line considers the thorns of a rose as a protective personality trait and makes a link between two unrelated instances: a rose and a sorrowful life. The result is a poetic line about the life of a rose that is short and full of sorrow. Assigning personality traits to an inanimate object illustrates poetic metaphor formation. The analogy was built between two instances, a person and a rose, by means of assigning the properties of the former to the latter. The effect of a metaphor is achieved via association, comparison and resemblance of these instances. A number of researchers see a metaphor as a source of selective comparisons that can offer new perspectives on a problem, highlight or create similarities to other domains, and yield insights for problem redefinition. For example, Kuhn (1993) suggests that in science, metaphors play the role of the building blocks of paradigms. These studies indicate that metaphor formation could be beneficial for creativity.

The question is how metaphors are generated. MacCormac (1986) argued that emotion provides the motivation for the production of creative metaphors. This idea has been tested in a number of experimental studies on metaphor formation (Fainsilber \& Ortony, 1987; Williams-Whitney et al., 1992). These studies showed that participants generate more novel metaphors when they are emotionally involved in the task. Furthermore, Miall (1987) demonstrated that patients with frontal lobe lesions reveal emotional problems and difficulties in forming metaphors. Summarizing the existing data on metaphor generation, Lubart and Getz (1997) proposed an emotional resonance mechanism by which the metaphor can be generated. According to this model, emotion-based endocepts that are attached to the specific concepts or images in memory communicate with each other by means of an automatic resonance mechanism that propagates an active emotional pattern through memory. A resonance detection threshold controls whether 
a resonance-activated endocept/concept enters consciousness. This model suggests that emotions link distant concepts in the process of metaphor formation. This consideration brings us back to Vygotsky's (1925/1971) emphasis on the role of emotions in the formation of the aesthetical reaction.

Last but not least, the link between conceptual multiplicity and creative thinking can be further supported with the case of synaesthesia. This is a neurologically based phenomenon, which creates an involuntary pattern of cross-modal association resulting from activation of an unstimulated sensory or cognitive modality in response to stimulation of other sensory or cognitive pathways. Synaesthetes report vivid experiences of taste or odour when hearing particular sounds (e.g., Rich \& Mattingley, 2002), perceiving letters or numbers as inherently coloured (e.g., Hubbard \& Ramachandran, 2005), associating numbers, days of the week and months of the year with personalities (e.g., Simner \& Hubbard, 2006) or precise special locations (e.g., Sagiv, Simner, Collins, Butterworth, \& Ward, 2006), and seeing colours when hearing music (e.g., Ward, Huckstep, \& Tsakanikos, 2006). An increasing number of psychometric and historiometric studies associate synaesthesia with creativity. Synaesthetes were found to outperform their nonsynaesthetic counterparts on tests of divergent thinking (Domino, 1989; Mulvenna, Hubbard, Ramachandran, \& Pollick, 2004). A number of prominent creative individuals have been identified as synaesthetes (Mulvenna \& Walsh, 2005) with a common list including the physicist Feynman (1988), the novelist Nabokov (1967), the composers Messian (Bernard, 1986) and Scriabin (Peacock, 1985) and the artists Hockney (Cytowic, 2002) and Kandinsky (Ione \& Tyler, 2003). It is plausible to assume that multimodal presentation of different conceptual planes may elicit synaesthetic-like experience in recipients (see discussion in the following section).

Thus, cognitive poetry aims at eliciting an aesthetical reaction by enriching poetic text with multiple meanings presented through multiple sensory modalities. It employs techniques developed in cognitive psychology to explicitly address cognitive processes underlying the construction of multiple conceptual planes. The following section discusses some of these techniques and illustrates them with examples.

\section{TECHNIQUES}

\section{Priming effect}

Knowledge representations are stored in conceptual memory. Everything we know, everything we have learnt is assumed to form a network of units of meaning (or conceptual features representing events, objects, properties, etc.). When we address one concept or another, the corresponding units of meaning become activated and share this activation with other units related to the given one. Therefore, conceptual memory is assumed 
to be a pattern of spreading activation (McClelland \& Rumelhart, 1985) over a large set of mutually linked units of meaning organized in conceptual networks (Lamb, 1999). These units may be activated by impulses coming from verbal cues, non-verbal experiences, such as auditory, visual, somaesthetic, and olfactory, or may be self-activated during an act of thinking in the absence of any stimuli (Paradis, 2000). Any sensory experience, as well as any product of our thought process, is stored as a pattern of neural activity and leaves a trace in our memory. The spreading activation mechanism transfers signals between conceptual features providing facilitation for related concepts and inhibition for unrelated ones. The activation of the conceptual features is assumed to be an unconscious process, and only those features that receive enough activation are selected for conscious processing.

This property of the conceptual system underlies the priming paradigm (Meyer \& Schvaneveldt, 1971), which has been one of the most commonly used techniques to explore the structure of mental representations, an area that continues to be one of the most widely studied in the domain of cognitive psychology. The basic concept behind this paradigm is that exposure to one stimulus influences a response to another stimulus. The priming technique sequentially presents stimuli of the same or different modality, consciously or subliminally, and positively or negatively related. Priming can occur following perceptual, conceptual or semantic stimulus presentation. Semantic priming is the most relevant with respect to poetic text presentation. It implies that when a word is presented, not only is its mental representation automatically activated, but also activation spreads to those words that are semantically related to or associated with the presented word (Collins \& Loftus, 1975; Collins \& Quillian, 1969). The semantic priming effect has been observed and reported in hundreds of studies and under many different experimental manipulations (for reviews, see McNamara \& Holbrook, 2003; Neely, 1991). Traditionally, the priming technique involves two types of stimuli: the prime and the target. The prime is assumed to influence the processing of the target. For example, in a classical priming experiment the word 'nurse' is recognized more quickly following the word 'doctor' than following the word 'bread'.

This technique can be effectively used to activate several psychic planes with opposite directionality, which according to Vygotsky (1925/1971) elicits cathartic experience. Elements of poetic text can be preceded by visual, auditory or verbal elements. For example, the project "Poor L. (to the accompaniment of A. S. Pushkin)"1 employs negative conceptual priming with subliminal presentation. Negative priming is caused by experi-

\footnotetext{
${ }^{1}$ This project is a result of the collaboration of the author with Valeriy Shafiro. The video of the project is posted on YouTube (https://youtu.be/EOuDv4rHJYc).
} 
encing the stimulus and then ignoring it (Mayr \& Buchner, 2007). In conceptual priming, the prime and the target belong to the same conceptual category. The stimuli in negative conceptual priming are supposed to reveal inherent contradiction. Subliminal presentation presents sensory stimuli below an individual's threshold for conscious perception (Loftus \& Klinger, 1992).

Thus, this project uses classical poetry by Pushkin (2002) "To..." (p. 67) as a subliminal prime, which is presented in such a way that the reader cannot read it, but registers it implicitly. The target text of the poem written by the author follows the prime line by line. This text conceptually contradicts Pushkin's classics: the latter presents the theme of sublime love and is written using a rapturous style; the former uses explicitly vulgar language to describe the unfortunate life of a provincial girl from a troubled family. Due to the subliminal presentation of Pushkin's poem, the reader develops a romantic, highly positive frame of mind. This effect is supported by the fact that this poem appears to be very dear to the Russian reader, because it is studied as a part of the Russian school curriculum, as the most romantic piece in Russian poetry. The target poem destroys this tranquility; the contradiction is especially dramatic considering the polar valence of these pieces. This contradiction is supposed to elicit cathartic experience and per Vygotsky (1925/1971) to reinforce the aesthetical reaction to the poetic text.

\section{Stroop effect}

Activation of oppositely oriented conceptual planes can be achieved with another technique largely used in cognitive psychology, the Stroop paradigm (Stroop, 1935). This is the most widely used test of selective attention (an ability to attend to some stimuli and to ignore others; Duncan, 1999). A typical Stroop task presents colour names printed in different colours, and asks participants to name the colour in which a word is printed. For example, the word "red" is presented in green, and the task is to name the colour in which the word is printed (i.e., green). The automatic behaviour (reading of the word for a colour name) interferes with the decision rule (naming of the font colour), and this behaviour needs to be suppressed. The test exploits the conflict between an automatic behaviour (i.e., reading) and a decision rule that requires this behaviour to be inhibited. Therefore, it taps into the ability to inhibit inappropriate responses and resist interference (Stroop effect). This effect arises from two processes working in opposite directions: facilitation and inhibition. Facilitation taps into ability to focus on the information when it is helpful, and inhibition refers to the ability to ignore the information when it is misleading. These cognitive mechanisms of selective attention are employed in construction of conceptual planes with different orientations. 
The Stroop paradigm implicates two modalities: verbal (poetic text) and visual (colour). These modalities may interfere with each other, which according to Vygotsky (1925/1971) elicits cathartic experience, or they may facilitate each other thereby enriching the verbal element with visual connotations. The Stroop effect is particularly useful in poetry aiming at triggering readers' visual imagery. Visual art establishes multidimensionality of a constructed image by introducing various visual elements simultaneously. Each element can be processed separately, but the viewer sees them at once. Poetry does not have this capacity; it requires sequential presentation and description of each narrative element. To elicit visual imagery, a poet needs to elaborate on each element separately and only then narrate them into a whole image. This process requires considerable time and cognitive effort, and may cause disruption in reading when the text becomes too lengthy. Recall for example a famous description of the shield of Achilles in Homer's (2012) Iliad, which stretched over 131 lines. For this reason poets handle visual imagery with caution. Introducing visual elements, specifically colour, to a poetic text may solve this problem. This technique is well utilized in visual poetry (see Edeline, 2012, for an overview). Edeline presents the most obvious example, in which colour words are printed in the same colour ('yellow' printed in yellow and 'blue' printed in blue).

To illustrate the working of the Stroop effect, I use a translation of my Russian poem originally published in black on white (Harhur, 2012). I apply different colours to accentuate the visual elements presented in the poem (see Appendix A). Establishing multiple conceptual planes is achieved by colour-text congruence (when a colour corresponds to the meaning of a word; e.g., the word 'stone' printed in grey) and incongruence (when a colour contradicts the meaning of the word; e.g., the word 'sun' printed in blue). An additional effect of this technique appears in that the use of colours hampers reading of the text. This encourages the reader to contemplate the meanings of each individual word, which may contribute to conceptual multiplicity and the visual imagery of the poem.

\section{Multimodal presentation}

Of particular interest to the present work is the neurocognitive research in synaesthesia which demonstrates that non-synaesthetes may recruit the same neural mechanisms as synaesthetes, but use them in a qualitatively different manner (Simner et al., 2005; Ward et al., 2006). A decreased inhibition model of synaesthesia (Cytowic \& Eagleman, 2009; Grossenbacher, 1997) implicates that synaesthetes and non-synaesthetes have the same rich connectivity in the brain. They differ only in the functioning of inhibition mechanisms, which suppress the cross-modal connections in the non-synaesthetic brain and keep them active in the synaesthetic one. The faulty inhibition may result in synaes- 
thetic-like experience, which can also be reached during meditative practice, deep absorption, while falling asleep, drug use (e.g., LSD use, Marks, 1978), or as a result of a psychological disorder (e.g., paranoid schizophrenia or Charles Bonnet syndrome; Cohen Kadosh \& Henik, 2007). These findings suggest that although the cross-modal connections are present in all brains, they reveal their synaesthetic-like functioning only as a result of the malfunctioning of the inhibition mechanisms. The weakening of the inhibition mechanism can be accomplished by the involvement of non-synaesthetes in implicit processing requiring no focus of attention. This processing can enrich cross-modal connectivity and consequently allow the non-synaesthetes to demonstrate synaesthetic-like behaviour. This consideration is supported by research showing decrease of thalamocortical inhibition in the synaesthetic brain, which could also be elicited by the weakening of attention mechanisms in a non-synaesthetic brain (Cytowic \& Eagleman, 2009; Eagleman \& Goodale, 2009; Grossenbacher, 1997).

I take the decreased inhibition model of synaesthesia as a starting point and process poetic text to explicitly disperse the recipient's attention. Thereby, I aim to weaken the inhibition mechanisms and elicit synaesthetic-like experience. The defocus of attention can be achieved by dividing one's attentional capacity among multiple tasks. This idea stems from cognitive research in divided attention (e.g., Loose, Kaufmann, Auer, \& Lange, 2003; Neisser \& Becklen, 1975; Spelke, Hirst, \& Neisser, 1976) demonstrating that simultaneous presentation of at least two tasks decreases performance on both of them. These findings were explained by the resource theory, postulating that an organism possesses limited processing capacity and has to select from the multitude of available sensory input (Broadbent, 1958). The optimal allocation of resources can be accomplished by splitting or rapid shifting of the attentional focus between different input sources, which has received the term divided attention (Parasuraman, 1998). Attention can be divided between locations in space, between features of a single or of several objects, and between stimuli in one or several sensory modalities (Braun, 1998).

The effect of divided attention is well known in art and literature. For example, Vygotsky (1925/1971) presented Christiansen's formula for the psychological life of a portrait:

It is the physiognomic incongruity of the various factors that makes up the expression of a face. Of course it is possible, and, speaking in abstract terms, also more natural to have the corners of the mouth, the eyes, and other parts of the face express the same feeling or emotion or mood. ... Then the entire portrait would resonate with the same tune. ... But then, like any tune, it would be devoid of life. This danger of consistency is why the painter makes the expression in one eye 
slightly different from that in the other, and makes the effect of the corners of the mouth different again, and so forth. However, it is not enough to paint different moods, expressions, and feelings; they must also harmonize with one another. ... The principal theme is given by the relationship between the eyes and mouth: the mouth talks and the eyes answer. Excitement, will, and tension are concentrated around the corners of the mouth, while the relaxed calm of the intellect prevails in the eyes... The mouth reveals the instincts and the driving forces of a man. The eye shows what he has become in his victory, defeat, or tired resignation. ... The physiognomic incongruency among the various details of the facial expression in a portrait is the basis for our emotional reaction. (Vygotsky, 1925/1971, pp. 193-194) If the portrait plays with incongruence within a single modality (i.e., visual), I used video to elicit incongruence between different sensory modalities. The video poem "Orpheus \& Orpheus"2 presents poetic text in both visual and auditory forms. The poem develops the theme from Greek mythology about Orpheus, a legendary musician, poet and prophet. Orpheus descends into the underworld of Hades for his deceased wife Eurydice. By his singing he enchants Hades's wife Persephone who convinces Hades to grant Orpheus permission to return Eurydice to the realm of the living. But only on one condition: during his journey from the underworld, Orpheus should not look back at Eurydice. Orpheus looks back. My poem conceptualizes Orpheus as an archetype of the poet. Eurydice in the realm of the dead is only a shadow, the imagination of the poet. Dialogue between Orpheus and Eurydice is a dialogue between the poet and his muse; that is, a dialogue with himself. This notion is presented in the video by two figures of the same male figure reciting both male and female parts. The dialogue takes place in Orpheus's mind for there is no other person in the scene (Eurydice is in his imagination). This notion is presented by lips moving out of synchrony with the audio track. The incongruence between the visual and auditory planes is meant to elicit aesthetical reaction to this work.

\section{Multilingual presentation}

Finally, the most obvious, although in my opinion not sufficiently explored technique, constructs poetic text using two or more languages. Vastly increased human mobility, communication technology, and the accelerating integration of the world economy has abolished geographic boundaries and brought together people from different cultural and linguistic backgrounds. The close interaction of people speaking different languages expo-

\footnotetext{
${ }^{2}$ This project was presented at the author's solo exhibition poARTree in G.A.D. Gallery Berlin. The video of the project is posted on YouTube (http://youtu.be/cYppQ7qDG8M). The poem was recorded in Russian; the English translation is available by clicking on Subtitles/CC button.
} 
nentially increases the growth of the multilingual population. This phenomenon has received sufficient consideration in scientific research, which provides a growing body of empirical investigation on multilingualism. It is however, generally disregarded in creative writing. To fill this gap, I present an elaborate scientific account of the phenomena of multiculturalism and multilingualism, and demonstrate how they can be appropriated in poetry.

Recall from the previous section, the discussion of the mental representations of related and unrelated concepts. The related conceptual representations tend to receive simultaneous activation over a number of repetitive occurrences in the perceptual input. These features form conceptual categories. The category formation takes place in the context of subjective experience. ${ }^{3}$ As a result of this experience, each person would be expected to develop a unique set of conceptual categories. However, due to a shared environment and comparable experience, we develop overlapping categories. These categories allow us to perceive the world in a relatively similar way and to communicate our experiences to each other by means of a common system of conventional tokens (e.g., language). Due to conceptual categories, although each one of us has a unique pattern of thoughts, we tend to show a remarkable consistency in the interpretation of environmental input. Categorical thinking allows us to efficiently process information, facilitate responses to familiar situations, and produce solutions to familiar problems.

At the same time, categorical thinking has a disadvantage for human cognition. In line with the earlier discussion, an individual's experience leaves an imprint on mental representations. According to Piaget (1936), the acquisition of a new experience may result in two types of processes: assimilation and accommodation of the incoming information. Assimilated information is adopted by existing conceptual categories so that these categories do not change. The accommodation of the information results in the modification of the existing categories. Alternatively, a new conceptual framework can be established, but this process requires greater cognitive effort and therefore is relatively uncommon. Thus, if the sensory or mental information cannot be accommodated by or assimilated into existing conceptual categories, and there is not enough mental capacity to form new categories, the information could be completely ignored and the experience could be lost. These considerations suggest that categorical thinking only permits an individual to process information that can be integrated into the standard conceptual category boundaries. This accounts for the above mentioned 'structured imagination'. The latter can be overcome by making the mind escape the boundaries of standard con-

\footnotetext{
${ }^{3}$ This work takes a mid-point position in the nature/nurture debate (see Ceci \& Williams, 1999, for an overview), and assumes that each individual has a distinct pattern of lifelong exposure to environmental stimuli as well as a unique set of predispositions to interpret environmental cues.
} 
ceptual categories. Kharkhurin (2011) suggested that this can be facilitated by an experience with different cultural settings. Although multicultural ${ }^{4}$ experience does not result in the complete renunciation of categorical thinking, it is argued that it facilitates the process of broadening of the category boundaries.

The argument that multicultural experience expands conceptual categories is based on the notion that categorical thinking is partially determined by the elements of a sociocultural environment. As was mentioned earlier, formation of conceptual categories takes place in the context of an individual's experience and therefore heavily relies on specific cues in one's environment. Cross-cultural studies in perception (e.g., Deregowski, 1989; Hudson, 1960) support this argument by showing that experience with specific environmental cues may stipulate the successful processing of sensory information. It is intuitively obvious that we gain most of our experience in a sociocultural context. Therefore, it is plausible to assume that conceptual category formation may be partially determined by sociocultural settings. If the specific sociocultural cues contribute to the formation of an individual's conceptual categories, experience with different cultures may result in qualitative modifications of the conceptual system such as the internalization of new concepts, the convergence and restructuring of one's existing conceptual representations and expansion of conceptual categories (de Groot, 2000; Pavlenko, 2000).

The studies in linguistic anthropology and cognitive linguistics elaborating on Whorf's (1956) linguistic relativity ${ }^{5}$ argue that thinking is shaped by linguistic categories that reflect specific discursive structures and practices as they are implemented in social institutions and cultural traditions (e.g., Lucy, 1997). In recent years this theme has been conferred by a number of researchers in multilingualism (e.g., de Groot, 2000; Paradis, 2000; Pavlenko, 2000). They argue that the conceptual systems of individuals who have acquired more than one language inevitably undergo adaptations influenced by the cultural and social contexts in which these languages were learned. Since cultural experience is deeply rooted in higher-order linguistic structures such as polysemy, metaphor, irony and other non-literal aspects of language, successful language acquisition is likely to be accompanied by the acquisition of cultural knowledge (in the form of schemas and frames). This knowledge in turn, modifies conceptual representation and organization in bilingual memory (Vaid, 2000).

\footnotetext{
${ }^{4}$ In this work, the term multicultural refers to direct and indirect experiences with various sociocultural settings which could be acquired through the interaction with the members of different cultures and/or through the acquisition of cultural knowledge in the media.

${ }^{5}$ Traditionally, the linguistic relativity or Sapir-Whorf hypothesis is presented as a postulate that language influences thought. Speakers of different languages should think and behave differently. A strong version of the hypothesis holds that language determines thought and that linguistic categories limit and determine conceptual categories. A weaker version states that the way language encodes cultural and cognitive categories influences the way people think. However, this traditional view appears to be a misconception largely accepted in scholarly circles. Since this theme falls beyond the scope of interest of the present work, I refer the interested reader to Pavlenko (2014) who provides an elaborate historical account of development and misrepresentation of the Sapir-Whorf hypothesis.
} 
Thus, multicultural experience boosts expansion of the category boundaries, which may facilitate simultaneous activation of multiple conceptual planes. This experience can be triggered by multilingual practice. ${ }^{6}$ There is an argument in the literature that this practice may result in establishing specific architectures of the mind that are likely to initiate language mediated concept activation (Kharkhurin, 2007, 2008; Kharkhurin \& Isaeva, 2014). The idea of this mechanism is based on the assumption that translation equivalents automatically activate each other through shared conceptual representations (e.g., concept mediated translation in Kroll and de Groot, 1997). Although translation equivalents share most of the conceptual features, these representations are not identical (e.g., Paradis, 1997). Variations in the conceptual representations of translation equivalents may result in the simultaneous activation of additional concepts, which eventually may produce a large pattern of activation over unrelated concepts from different categories. The activation of these concepts is assumed to take place through the lemmas representing the translation equivalents in multiple languages and/or through the word forms (e.g., phonetic, orthographic) shared by these languages. The elaborate language mediated concept activation triggers simultaneous processing of a large number of unrelated concepts from different categories. Hence, the mere use of several languages may facilitate expansion of the category boundaries, which per previous discussion may result in conceptual multiplicity.

Similarly, the alternation and mixing of different languages in the same episode of speech production - termed code-switching (or translanguaging; Garcia \& Li, 2014) has been argued to be a creative act (e.g., Kharkhurin \& Li, 2014; Li \& Wu, 2009). Linguists working in the ethnography tradition investigated the use of translanguaging in diverse contexts, from literature and drama, to pop songs, the new media and public signs (e.g., Androutsopoulos, 2013; Chik, 2010; Jonsson, 2005; Sebba, Jonsson, \& Mahootian, 2012). These studies took code-switching not simply as a juxtaposition of different grammatical structural elements, but as an expressive and creative performance. Bhatia and Ritchie (2008) revealed various facets of creativity through code-switching as it manifests itself in the day-to-day verbal behaviour of a multilingual person. They argued that codeswitching is essentially an 'optimizing' strategy rendering a wide variety of new meanings which the separate linguistic systems are incapable of rendering by themselves.

The aim of this lengthy discussion is to bring the reader to an important conclusion: the mere use of several languages within one poetic text may stimulate activation of multiple distant conceptual planes and thereby increase the reader's aesthetical reaction.

\footnotetext{
${ }^{6}$ I define multilinguals as individuals who are fluent in all their languages, but also those who actively use, or attempt to use more than one language, even if they have not achieved fluency in all of them (Kroll \& de Groot, 1997).
} 
This technique has been known since Camillo Scroffa (Fidenziana poetry; Scroffa, 1568) who wrote Petrarchan parodies applying Italian form and syntax to Latin words, and the macaronic poets who wrote comic verses consisting of Italian words used according to Latin form and syntax. Well-known examples of non-humorous macaronic verse are Byron's Maid of Athens, ere we part in English with a Greek refrain ("Zwń бã sáyaாஸ̃"; "My life, I love you!"; Eliot, 2010, p. 815) and a $14^{\text {th }}$ century carol In Dulci Jubilo (In sweet rejoicing) in mixed German and Latin verse attributed to Heinrich Suso. Some contemporary poets use this technique as well, but they continue the humorous tradition of macaronic verses. For example, Cleary's (2004) poem What Can I C'est? combines English and French:

My auntie Michelle is big in the BON

(As well as the hip and the thigh).

And when she exhales, OUI haul out our sails

And ride on the wind of VERSAILLES.

In cognitive poetry, multilingual presentation of poetic text aims at constructing multiple meanings. For example, in one of my poems from the book BCE (Harhur, 2012, p. 90; written in Russian), I formed a word using Russian and German syllables, respectively: $N^{\prime} \dot{t}$ / (meaning in Russian plural you) and /dox/ (meaning in German something like 'on the contrary' in response to a negative question), together a Russian word $/ V^{\prime} \dot{i d} \mathrm{~d} \mathrm{x} /$ (meaning in Russian exhalation):

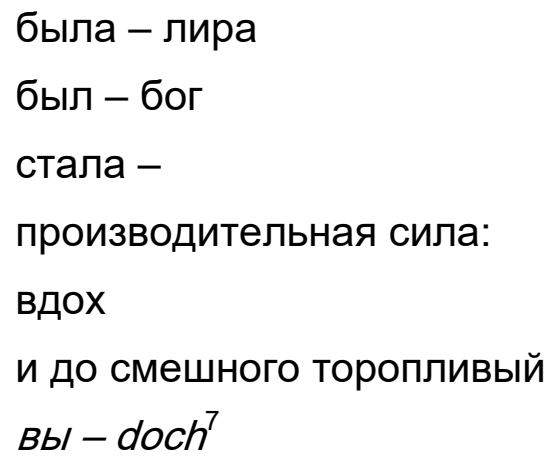

The poem raises an existential question about the meaning of human life. The acrimonious answer suggests an individual's corporal mechanistic lifestyle; people's life is reduced to mere productive functions ('productive force' in the poem). The mechanical pace of an individual is presented through repetitive use of words 'inhalation' and 'exhalation'; this is how our body works: inhale - exhale. The German word 'doch' incorporated into the word 'exhalation' creates a contradiction; it introduces the sense of breakage in a well-built mechanism.

\footnotetext{
${ }^{7}$ This is a fragment of the poem, where the target word is selected in italics. In the following, I present my English translation: there was a harp, there was God, now, productive force: inhalation, and ridiculously hurried, ex - halation
} 
Another example is a poetry film The Lion of God. ${ }^{8}$ Here a poetic text unfolds both vertically and horizontally. A vertical reading introduces female, male, and the child's principles, respectively. A horizontal reading presents a dialogue, which expresses the union of female and male principles being realized in the process of conception. Thereby, the poem creates a multidimensional verbal space, in which male and female principles are presented vocally and in which the unvoiced child's principle is presented visually as a part of the video. The multidimensional character of this work gathers momentum through trilingual representation: German voice of the mother, Russian voice of the father and English unborn voice of the child. To increase the effect of conceptual multidimensionality, the video superimposes the respective father's and mother's parts presented aurally and the child's part presented visually.

\section{CONCLUSION}

It is evident that cognitive poetry brings poetic text far beyond the boundaries of traditional poetics, and even beyond the verbal domain. In this endeavour, it encourages processing of the text with multimedia technologies. Cognitive poetry targets cognitive processes underlying and triggering an individual's creative thinking. For this reason, it is crucial to establish the scientific foundation of the genre and to determine what techniques can be employed to activate specific cognitive functioning. This article presented the theoretical framework and identified four techniques that can be applied to poetic text. The aim is to establish contradicting conceptual planes, which elicits cathartic experience. However, the techniques that can be used in cognitive poetry are not limited to these four. For example, the complication of the plot, which per Vygotsky (1925/1971) elicits aesthetical reaction to a work of art, can be achieved by combining two texts with oppositely directed messages into one. This can be illustrated by the Moving Verses project, ${ }^{9}$ which brings the reader to the cathartic experience of two conflicting emotions and then resolves the conflict by disclosing underlying emotional flows. The reader uncovers that in fact, this poem consists of two texts: one declaring passionate love and the other expressing an ultimate disgust.

Another technique aims at hampering the reading/viewing process. The intention is to encourage the reader to contemplate on each individual word and to reveal its inherent value. In the Broken Vessels project, the readers/viewers hamper the reading themselves. Ac-

\footnotetext{
${ }^{8}$ This project is the result of a collaboration between the author as a poet and Zlatan Filipović as a video artist who each from the perspective of their respective genres - developed the theme of parenthood. The project was submitted to ZEBRA Poetry Film Festival Berlin. The video of the project is posted on YouTube (http://youtu.be/YAMfwTQMROU). The English translation is available by clicking on Subtitles/CC button.

${ }_{9}$ Unfortunately, this project is available only in Russian, but the interested reader can watch it on the author's Poetry Server (http://harhur.com/cogpoetry/moverses/moverse.html) to see the technique of moving verses.
} 
tually, they play a central role in this project thereby making it an art happening. ${ }^{10}$ In this project, each verse of the poem (see Appendix B) presents a sustainable virtue given to people. The poem is printed on black paper covered by thin glass to create a mirror reflection. The poem covers the floor of the exhibition hall. The visitors walk into the hall. They see their own reflection masking the poem. This act presents the inability of people to see the virtues because of their egocentric attitudes. By walking on the glass the visitors break it. Broken glass shards cut the paper on which the poem is printed thereby hampering reading of the poem. This act symbolizes people destroying the path to existential completeness. Thus, the following parallel is constructed: The visitors are unable to read the poem because it is masked by their mirror reflection. Even when the glass breaks and they see that something is written underneath, they cannot comprehend it because the text is broken into pieces. The poem in combination with the act of breaking the glass should make the visitors aware of the fact that their selfishness eliminates meaning from their life.

Further, cognitive psychology supplies other techniques that can be successfully used in the processing of poetic text. In the following, I sketch their potential use. Splitbrain studies (e.g., Sperry, 1968) were conducted with epilepsy patients whose corpus callosum was cut to prevent seizures from spreading. To determine how each hemisphere processes visual input, these patients were presented with textual stimuli on a large screen so that the left part of the screen corresponded to the left visual field (controlled by the right hemisphere) and the right part of the screen - to the right visual field (controlled by the left hemisphere). It was found that the left and right hemispheres process information separately and the corpus callosum serves as a bridge between the hemispheres, which channels information from one to the other. This technique can be used for the simultaneous presentation of different elements (verbal and nonverbal) of a poem. These elements can be projected onto a large screen similar to the one in the split-brain paradigm. In this case, one element undergoes initial processing by the left hemisphere (traditionally associated with verbal processing) and the other - by the right hemisphere (traditionally associated with spatial processing). The outcome may elicit conceptual multiplicity, and per earlier discussion, aesthetical reaction to the poem.

\footnotetext{
${ }^{10}$ The project raises awareness about the potential causes of psychological distress and calls for re-thinking of an individual's existential values. The major theme of the project evolves around people's egocentric behaviour, which undermines their existentially sustainable development. People were granted sustainable virtues, which were intended to establish a path to existential completeness. People do not see these virtues, because they are occupied with their own reflection, their ego. This egocentric behaviour masks these virtues thereby giving rise to an existential void (Frankl, 2000). What they see instead is the reflection of their own worries. Only in the state of flow (cf. Csíkszentmihályi, 1990), can people see scattered pieces of these virtues. However, even in these moments they are not able to construct the full picture and therefore remain in confrontation with the givens of existence. The project was exhibited at The Big Picture art exhibition in Dubai (UAE). The video of the project is posted on YouTube (https://youtu.be/bqWAilQtxOA).
} 
In a series of brain stimulation studies, epilepsy patients undergoing open brain surgery received direct stimulation of different brain areas along the surface. Depending on the brain region being stimulated, the patients reported visual images, tingling sensations, muscular twitches and other reactions (Penfield \& Roberts, 1959). Noninvasive brain stimulation techniques (e.g., Wagner, Valero-Cabre, \& Pascual-Leone, 2007) have the potential to be used with nonclinical populations. In this case, one may think about using this technique in combination with the presentation of a poetic text. Since direct stimulation of the brain may alter a reader's perception, it can be used to modulate the interpretation of the text.

Eye-tracking devices measure eye positions and eye movements. They provide exact information in relationto what a person looks at. An eye tracker can be used to vary the presentation of poetic text depending on the person's direction and/or pace of reading. Imagine that poetic text is a dynamic space, which changes as the reader carries on. In a similar fashion, the measurements of psychological or physiological arousal (e.g., brain imaging and galvanic skin response) indicating a reader's emotional state, can be used to manipulate the text fragments. A prototype of this technique can be found in the The Poem of Forking Paths. ${ }^{11}$ This hypertext presents a map of forking pathways, which prompts readers to select an arbitrary pathway based on their visual preferences. The readers find the constituents of the poetic text at the intersections of these pathways. They are presented as white rectangles and the readers need to click on them to reveal short passages combining verbal and visual elements. The order of openings modulates the reading and therefore, the meaning of the poem.

It is evident that although the methodology discussed in this article has been conceived for a poetic text, it can be successfully applied to literature, visual art, music, etc. The only condition that needs to be satisfied is the reference to cognitive psychology, either theoretical or methodological.

One final note, an important question concerning the aesthetic value of cognitive poetry needs to be raised. The genre claims to elicit aesthetical reactions to poetic text, but does it produce this effect? The answer to this question deserves a more detailed consideration in a separate work, in which the products of cognitive poetry can be evaluated along four criteria of creativity: originality, utility, aesthetics and authenticity (Kharkhurin, 2014).

\footnotetext{
${ }^{11}$ This project is presented at the author's Poetry Server (http://www.harhur.com/cogpoetry/parents/index.html).
} 


\section{REFERENCES}

Androutsopoulos, J. (2013). Networked multilingualism: Some language practices on Facebook and their implications. International Journal of Bilingualism. doi: $10.1177 / 1367006913489198$

Aristotle. (2012). Poetics (J. Sachs, Trans.). Indianapolis, IN: Hackett Publishing Company, Incorporated.

Bernard, J. W. (1986). Messiaen's synaesthesia: The correspondence between color and sound structure in his music. Music Perception, 4, 41-68.

Bhatia, T. K., \& Ritchie, W. C. (2008). The Bilingual Mind and Linguistic Creativity. Journal of Creative Communications, 3, 5-21. doi: 10.1177/097325860800300102

Braun, J. (1998). Divided attention: Narrowing the gap between brain and behavior. In R. Parasuraman (Ed.), The attentive brain (pp. 327-351). Cambridge, MA: MIT Press.

Broadbent, D. E. (1958). Perception and communication. Madison, WI: Pergamon Press.

Ceci, S. J., \& Williams, W. M. (1999). The nature-nurture debate: The essential readings. Malden, MA US: Blackwell Publishing.

Chik, A. (2010). Creative multilingualism in Hong Kong popular music. World Englishes, 29, 508-522. doi: 10.1111/j.1467-971X.2010.01678.x

Cleary, B. P. (2004). Rainbow Soup: Adventures in Poetry. Minneapolis, MN: Carolrhoda Books.

Cohen Kadosh, R., \& Henik, A. (2007). Can synaesthesia research inform cognitive psychology? Trends in Cognitive Psychologys, 11, 177-184.

Collins, A. M., \& Loftus, E. F. (1975). A spreading-activation theory of semantic processing. Psychological Review, 82, 407-428.

Collins, A. M., \& Quillian, M. R. (1969). Retrieval time from semantic memory. Journal of Verbal Learning and Verbal Behavior, 8, 240-247.

Csíkszentmihályi, M. (1990). Flow: The Psychology of Optimal Experience. New York, NY: HarperCollins.

Cytowic, R. E. (2002). Synaesthesia: A union of the senses. Cambridge, MA: MIT Press.

Cytowic, R. E., \& Eagleman, D. M. (2009). Wednesday is indigo blue: Discovering the brain of synesthesia. Cambridge, MA US: MIT Press.

de Groot, A. M. B. (2000). On the source and nature of semantic and conceptual knowledge. Bilingualism: Language and Cognition, 3, 7-9.

Deregowski, J. B. (1989). Real space and represented space: Cross-cultural perspectives. Behavioral and Brain Sciences, 12, 51-119. 
Domino, G. (1989). Synaesthesia and creativity in fine arts students: An empirical look. Creativity Research Journal, 2, 17-29.

Duncan, J. (1999). Attention. In F. C. Keil \& R. A. Wilson (Eds.), The MIT Encyclopedia of the Cognitive Psychologys. Cambridge, MA: MIT Press.

Eagleman, D. M., \& Goodale, M. A. (2009). Why color synesthesia involves more than color. Trends in Cognitive Psychologys, 13, 288-292.

Edeline, F. (2012). The use of colour in visual poetry. Óbuda University e-Bulletin, 3, 285-299.

Eliot, C. W. (Ed.). (2010). English Poetry II: Collins to Fitzgerald (Vol. XLI). New York, NY: Cosimo, Incorporated.

Fainsilber, L., \& Ortony, A. (1987). Metaphorical uses of language in the expression of emotions. Metaphor \& Symbolic Activity, 2, 239-250.

Feynman, R. (1988). What do you care what other people think? Further adventures of a curious character. New York, NY: Norton.

Frankl, V. E. (2000). Man's search for ultimate meaning. Cambridge, MA: Perseus.

Garcia, O., \& Li, W. (2014). Translanguaging: Language, Bilingualism and Education. Basingstoke: Palgrave.

Grossenbacher, P. G. (1997). Perception and sensory information in synaesthetic experience. In S. Baron-Cohen \& J. E. Harrison (Eds.), Synaesthesia: Classic and contemporary readings (pp. 148-172). Malden, MA: Blackwell Publishing.

Guilford, J. P. (1967). The nature of human intelligence. New York: McGraw-Hill.

Harhur, T. (2012). BCE. Moscow, Russia: E.Ra.

Homer (2012). The Iliad (S. Mitchell, Trans.). New York, NY: Atria Books.

Hubbard, E. M., \& Ramachandran, V. S. (2005). Neurocognitive mechanisms of synesthesia. Neuron, 48, 509-520.

Hudson, W. (1960). Pictorial depth perception in sub-cultural groups in Africa. Journal of Social Psychology, 52, 183-208.

lone, A., \& Tyler, C. (2003). Neurohistory and the arts: Was Kandinsky a synesthete? Journal of the History of Neuroscience, 12, 223-226.

Jonsson, C. (2005). Code-switching in Chicano Theater. Umeå, Sweden: Umeå University Press.

Kasof, J. (1997). Creativity and breadth of attention. Creativity Research Journal, 10, 303-315. Kharkhurin, A. V. (2007). The role of cross-linguistic and cross-cultural experiences in bilinguals' divergent thinking. In I. Kecskes \& L. Albertazzi (Eds.), Cognitive Aspects of Bilingualism (pp. 175-210). Dordrecht, The Netherlands: Springer. 
Kharkhurin, A. V. (2008). The effect of linguistic proficiency, age of second language acquisition, and length of exposure to a new cultural environment on bilinguals' divergent thinking. Bilingualism: Language and Cognition, 11, 225-243.

Kharkhurin, A. V. (2009). The role of bilingualism in creative performance on divergent thinking and Invented Alien Creatures tests. Journal of Creative Behavior, 43, 59-71.

Kharkhurin, A. V. (2011). Conceptual freedom of the globalized mind: Multicultural experiences enhance human cognition through the expansion of conceptual categories. Journal of Consciousness Studies, 18, 66-83.

Kharkhurin, A. V. (2014). Creativity.4in1: Four-criterion construct of creativity. Creativity Research Journal, 26, 338-352. doi: 10.1080/10400419.2014.929424

Kharkhurin, A. V., \& Isaeva, M. G. (2014). Language mediated concept activation in bilingual memory as a facilitation mechanism of creative behavior. Paper presented at the The 3rd International Conference on the Interaction of Language and Cultures, Cherepovets, Russia.

Kharkhurin, A. V., \& Li, W.(2014). The role of code-switching in bilingual creativity. International Journal of Bilingual Education and Bilingualism, 1-17. doi: 10.1080/13670050.2014.884211 Koestler, A. (1964). The act of creation. Lewiston, NY: Macmillan.

Koestler, A. (1968). The ghost in the machine. Lewiston, NY: Macmillan.

Kroll, J. F., \& de Groot, A. M. B. (1997). Lexical and conceptual memory in the bilingual: Mapping form to meaning in two languages. In A. M. B. de Groot \& J. F. Kroll (Eds.), Tutorials in bilingualism: Psycholinguistic perspectives (pp. 169-199). Hillsdale, NJ: Erlbaum.

Kuhn, T. S. (1993). Metaphor in science. In A. Ortony (Ed.), Metaphor and thought (2nd ed., pp. 137-163). New York: Cambridge University Press.

Lamb, S. (1999). Pathways of the brain. Amsterdam: John Benjamins.

Li W., \& Wu, C.-J. (2009). Polite Chinese children revisited: Creativity and the use of codeswitching in the Chinese complementary school classroom. International Journal of Bilingual Education and Bilingualism, 12, 193-211. doi: 10.1080/13670050802153210

Loftus, E. F., \& Klinger, M. R. (1992). Is the unconscious smart or dumb? American Psychologist, 47, 761-765. doi: 10.1037/0003-066X.47.6.761

Loose, R., Kaufmann, C., Auer, D. P., \& Lange, K. W. (2003). Human prefrontal and sensory cortical activity during divided attention tasks. Human brain mapping, 18, 249-259. doi: $10.1002 / \mathrm{hbm} .10082$

Lubart, T. I. (2000). Models of the creative process: past, present and future. Creativity Research Journal, 13, 295-308.

Lubart, T. I., \& Getz, I. (1997). Emotion, metaphor and the creative process. Creativity Research Journal, 10, 285-301. 
Lucy, J. A. (1997). Linguistic relativity. Annual Review of Anthropology, 26, 291-312.

MacCormac, E. R. (1986). Creative metaphors. Metaphor \& Symbolic Activity, 1, 171-184.

Marks, L. E. (1978). The unity of the senses: Interrelations among the modalities. New York: Academic Press.

Mayr, S., \& Buchner, A. (2007). Negative Priming as a Memory Phenomenon. Zeitschrift für Psychologie / Journal of Psychology, 215, 35-51. doi: 10.1027/0044-3409.215.1.35 McClelland, J. L., \& Rumelhart, D. E. (1985). Distributed memory and the representation of general and specific information. Journal of Experimental Psychology: General, 114, 159-188.

McNamara, T. P., \& Holbrook, J. B. (2003). Semantic memory and priming. In A. F. Healy \& R. W. Proctor (Eds.), Handbook of Psychology (Vol. 4, pp. 447-474). New York: Wiley.

Mednick, S. A. (1962). The associative basis of the creative process. Psychological Review, 69, 220-232.

Mednick, S. A., \& Mednick, M. T. (1967). Examiner's manual: Remote Associates Test. Boston: Houghton Mifflin.

Mendelsohn, G. A. (1976). Associative and attentional processes in creative performance. Journal of Personality, 44, 341-369.

Meyer, D. E., \& Schvaneveldt, R. W. (1971). Facilitation in recognizing pairs of words: Evidence of a dependence between retrieval operations. Journal of Experimental Psychology, 90, 227-234.

Miall, D. S. (1987). Metaphor and affect: The problem of creative thought. Metaphor \& Symbolic Activity, 2, 81-96.

Mulvenna, C., \& Walsh, V. (2005). Synaesthesia. Current Biology, 15, 399-400.

Mulvenna, C. M., Hubbard, E. M., Ramachandran, V. S., \& Pollick, F. (2004). Synaesthesia and creativity. Journal of Cognitive Neuroscience, 16, 188.

Nabokov, V. (1967). Speak, memory: An autobiography revisited. New York, NY: Vintage Books. Neely, J. H. (1991). Semantic priming effects in visual word recognition: A selective review of current findings and theories. In D. Besner \& G. W. Humphreys (Eds.), Basic processes in reading: Visual word recognition (pp. 264-336). Hillsdale, NJ: Erlbaum.

Neisser, U., \& Becklen, R. (1975). Selective looking: Attending to visually specified events. Cognitive Psychology, 7, 480-494. doi: http://dx.doi.org/10.1016/0010-0285 (75)90019-5

Paradis, M. (1997). The cognitive neuropsychology of bilingualism. In A. M. B. de Groot \& J. F. Kroll (Eds.), Tutorials in bilingualism: Psycholinguistic perspectives (pp. 331354). Hillsdale, NJ: Erlbaum. 
Paradis, M. (2000). Cerebral representation of bilingual concepts. Bilingualism: Language and Cognition, 3, 22-24.

Parasuraman, R. (1998). The attentive brain: issues and prospects. In R. Parasuraman (Ed.), The attentive brain (pp. 3-15). Cambridge, MA: MIT Press.

Pavlenko, A. (2000). New approaches to concepts in bilingual memory. Bilingualism: Language and Cognition, 3, 1-4.

Pavlenko, A. (2014). The Bilingual mind: And what it tells us about language and thought. New York, NY: Cambridge University Press.

Peacock, K. (1985). Synesthetic perception: Alexander Scriabin's color hearing. Music Perception, 2, 483-506.

Penfield, W., \& Roberts, L. (1959). Speech and brain mechanisms. Princeton, NJ, US: Princeton University Press.

Piaget, J. (1936). La naissance de l'intelligence chez l'enfant. Oxford, UK: Delachaux et Niestlé.

Plotnik, A. (2007). Spunk \& bite: A writer's guide to bold, contemporary style. New York, NY: Random House Reference.

Pushkin, A. S. (2002). Collected narrative and lyrical poetry (W. Arndt, Trans.). Woodstock, NY: Ardis.

Rich, A. N., \& Mattingley, J. B. (2002). Anomalous perception in synaesthesia: A cognitive neuroscience perspective. Nature Reviews Neuroscience, 3, 43-52.

Rothenberg, A. (1979). The emerging goddess: The creative process in art, science and other fields. Chicago, IL: University of Chicago Press.

Rothenberg, A. (1996). The Janusian process in scientific creativity. Creativity Research Journal, 9, 207-231.

Sagiv, N., Simner, J., Collins, J., Butterworth, B., \& Ward, J. (2006). What is the relationship between synaesthesia and visuo-spatial number forms? Cognition, 101, 114-128.

Scroffa, C. (1568). I cantici di Fidentio ristampati con aggionta d'alcune uaghe compositioni nel medesimo.

Sebba, M., Jonsson, C., \& Mahootian, S. (2012). Language mixing and code-switching in writing : approaches to mixed-language written discourse. New York: Routledge.

Silvia, P. J., \& Beaty, R. E. (2012). Making creative metaphors: The importance of fluid intelligence for creative thought. Intelligence, 40, 343-351.

Simner, J., \& Hubbard, E. M. (2006). Variants of synesthesia interact in cognitive tasks: Evidence for implicit associations and late connectivity in cross-talk theories. Neuroscience, $143,805-814$. 
Simner, J., Ward, J., Lanz, M., Jansari, A., Noonan, K., Glover, L., \& Oakley, D. A. (2005). Non-random associations of graphemes to colours in synaesthetic and nonsynaesthetic populations. Cognitive Neuropsychology, 22, 1069 - 1085.

Spelke, E., Hirst, W., \& Neisser, U. (1976). Skills of divided attention. Cognition, 4, 215230. doi: http://dx.doi.org/10.1016/0010-0277(76)90018-4

Sperry, R. W. (1968). Hemisphere deconnection and unity in conscious awareness. American Psychologist, 23, 723.

Stockwell, P. (2002). Cognitive Poetics: An Introduction. London, UK: Routledge.

Stroop, J. R. (1935). Studies of interference in serial verbal reactions. Journal of Experimental Psychology, 18, 643-662.

Tsur, R. (1992). Toward a theory of cognitive poetics. Amsterdam, NL: North-Holland.

Vaid, J. (2000). New approaches to conceptual representations in bilingual memory: The case for studying humor interpretation. Bilingualism: Language and Cognition, 3, 28-30.

Vygotsky, L. S. (1925/1971). Psychology of art. Cambridge, MA: MIT Press.

Wagner, T., Valero-Cabre, A., \& Pascual-Leone, A. (2007). Noninvasive Human Brain Stimulation. Annual Review of Biomedical Engineering, 9, 527-565. doi: doi:10.1146/ annurev.bioeng.9.061206.133100

Ward, J., Huckstep, B., \& Tsakanikos, E. (2006). Sound-colour synaesthesia: To what extent does it use cross-modal mechanisms common to us all? Cortex, 42, 264-280.

Ward, T. B. (1994). Structured imagination: The role of category structure in exemplar generation. Cognitive Psychology, 27, 1-40.

Ward, T. B., Patterson, M. J., Sifonis, C. M., Dodds, R. A., \& Saunders, K. N. (2002). The role of graded category structure in imaginative thought. Memory \& Cognition, 30, 199-216.

Ward, T. B., Smith, S. M., \& Vaid, J. (1997). Creative thought: An investigation of conceptual structures and processes. Washington, D.C.: American Psychological Association.

Whorf, B. L. (1956). Language, thought, and reality: selected writings. Cambridge, MA: Technology Press of Massachusetts Institute of Technology.

Williams-Whitney, D., Mio, J. S., \& Whitney, P. (1992). Metaphor production in creative writing. Journal of Psycholinguistic Research, 21, 497-509. 


\section{APPENDIX A}

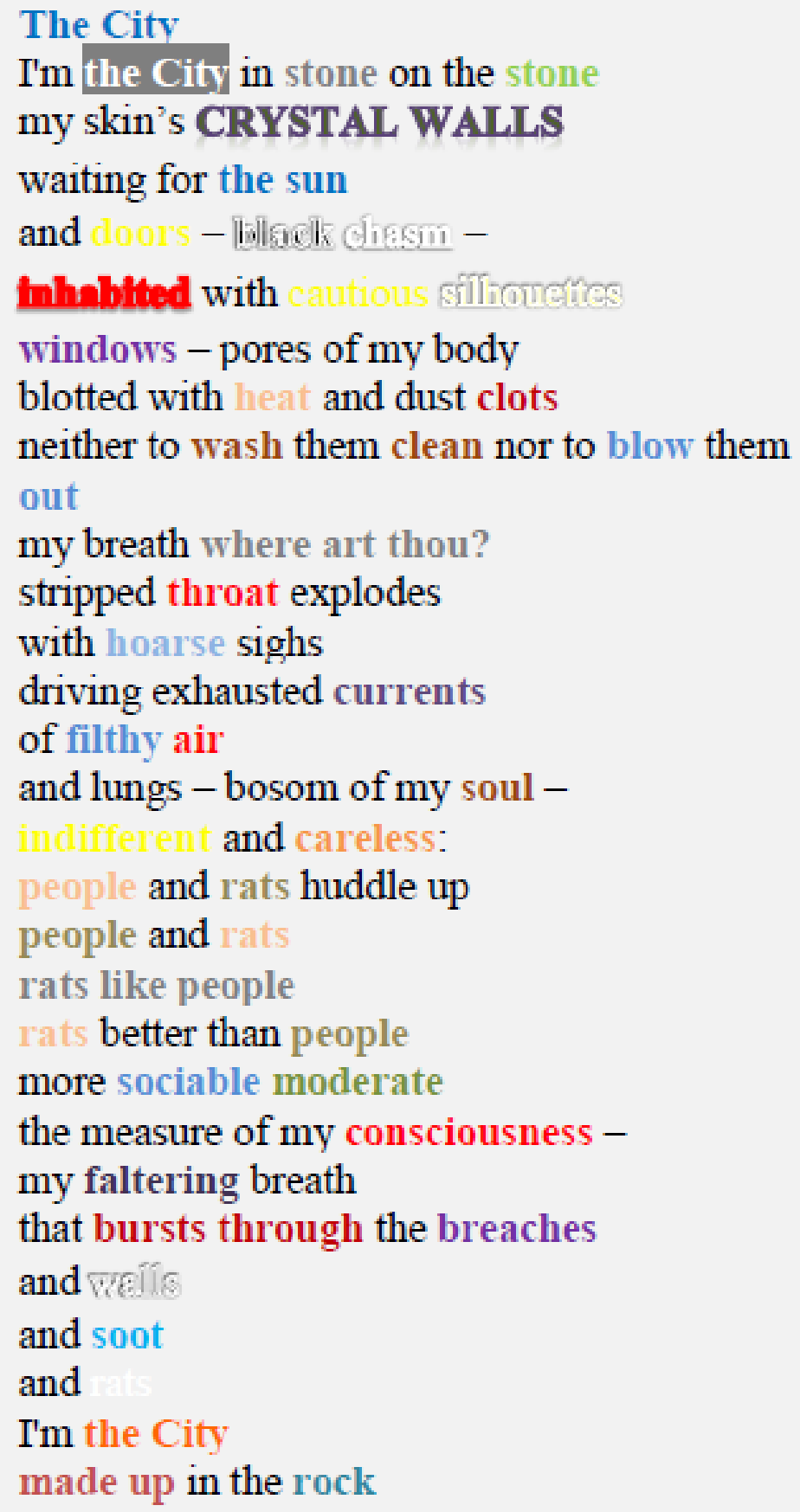


this is the left ear filled with anticipation of mature thought woman's joy - the moment of conception motherhood - the joy of acceptance comprehension: the mother of children does rejoice but lack harmony

this is severe might of judgment the concentration of supreme forces as if the right hand that gives was protected by the left one that strikes to prevent squandering of the goodness but instead it's all atrocity

this is the eternal resistance to all influences on one's path it's not dissoluteness but sincerity the confidence in balanced motion the steadfast step of the left foot of all who believe in predestination

\section{APPENDIX B}

this is the will to elongate countenance of the pleasure of the ancient of days the white light has marked the crown at birth the time passes by the gaze becomes firmer sharper and the mind - stuffed with properties

this is the central trunk - the homonyms coalesce therein: the supreme intellect has penetrated the depth of his sensual essence no one would condemn if knew this relation like adam knew his wife eve but lechery has been authorized here

this is the instant of beauty and harmony of might and benevolence the soul acquires its purpose in splendor of the body created for love - for love but not for agonizing sex

this is the pillar bridging heaven and earth the foundation of the universe -

the righteous man who related all elements to their procreative power

in the form of the reproductive organ that carries the sign of covenant - the circumcision

instead of assembly of the souls hanging out instead of actualizing speech small-talk

he has revealed his presence he lowered himself like a woman exposing herself and being trampled on

there is no kingdom

without people

but the people

in its vain search for permanence

tramples on the revealed

he created his world as the kingdom

but the path to the king is forgotten this is a patch of lightning bolt rushing about the right ear lobe - an earring scatters temptation of inspiration but the path of self-nullification is forgotten and - unwilling to understand the wisdom of the world is masked with irony

this is the right hand raised to construct the world with loving-kindness the love given to abraham strove to unconditionally bestow largesse but the goodness has been diverted by malignant gossip

this is eternal victory over all obstacles on one's path it's not aggression but persistence the supreme self-confidence the assertive step of the right foot of all who strive to rectify the world

\section{Corresponding author at: Anatoliy V. Kharkhurin, Ph.D., Department of International Studies, American University of Sharjah, P.O. Box 26666, Sharjah, UAE} E-mail: akharkhurin@aus.edu

CCopyright by Faculty of Pedagogy and Psychology, University of Bialystok,

20 Swierkowa St., 15-328 Bialystok, Poland

tel. +48857457283 